\title{
Goldfish intestinal microflora determined with fluorescently labeled rRNA-targeted oligonucleotide probes
}

\author{
HARUO SUGITA, ${ }^{1 *}$ AND MAIDIE ASFIE ${ }^{1}$ \\ 'Department of Marine Science and Resources, Nihon University, Fujisawa, Kanagawa 252-8510, Japan \\ (sugita@brs.nihon-u.ac.jp)
}

\section{KEY WORDS: intestinal bacteria, FISH method, microflora, goldfish}

\section{INTRODUCTION}

Although culture technique for the isolation of microorganisms from the intestinal tract is the sole source of intestinal microflora, identification and characterization of the resulting isolates based on phenotypic properties is time-consuming and labor intensive. In addition, microbial cells in the viable but not culturable (VBNC) state could not be detected by the culture technique. Recently, the advent of molecular tools has greatly expanded the ability to determine the intestinal microflora." Therefore, this study was undertaken to characterize intestinal microflora of goldfish Carassius auratus, using the fluorescent in situ hybridization (FISH) method.

\section{MATERIALS AND METHODS}

Five specimens of goldfish (15-61 $\mathrm{g}$ body weight), which had been reared in $47 \mathrm{~L}$-glass aquaria with water recirculating systems, were used in this study. The fecal pellet hanging on the fish anus was recovered and processed according to the procedures of $\mathrm{Manz}^{2)}$ and Santos Domingo. ${ }^{3)}$ Briefly, the fecal sample was fixed with nine volumes of $4 \%(\mathrm{w} / \mathrm{v})$ paraformaldehyde in $100 \mathrm{mM}$ phosphate buffered saline $(\mathrm{pH} 7.3)$ for at least $3 \mathrm{~h}$ at $4^{\circ} \mathrm{C}$, and homogenated with sterile tissue grinders. Aliquots from homogenates were stained with 4, 6-diamidino-2-phenylindole (DAPI) to determine a total number of microbial cells. ${ }^{1)}$ The fecal homogenates were vigorously vortexed and centrifuged at $8000 \times \mathrm{g}$ for $1 \mathrm{sec}$ to remove eukaryotic tissues and debris. The supernatant was centrifuged for $1 \mathrm{~min}$ at $6800 \times \mathrm{g}$, and the pelleted cells were preserved in a 1:1 mixture of PBS and ethanol at $-20^{\circ} \mathrm{C}$. Aliquots of the fixed cell suspension were spread on a gelatin-coated slide ${ }^{1)}$ over an area of $5 \mathrm{~mm}$ in diameter, dried and dehydrated by successive passages through 50,80 and $98 \%$ ethanol washes. Cells were hybridized separately with each probe at $37^{\circ} \mathrm{C}$ for $16 \mathrm{~h}$, and then stained with DAPI to determine a total number of microbial cells per microscopic

field. ${ }^{3)}$ Fluorescing cells were counted under a BX50 model epifluorescence microscope (Olympus) equipped with a $100 \mathrm{~W}$ mercury light source and appropriate filter sets.

A total of tetramethylrhodamine labeled rRNA-targeted oligonucleotides, ${ }^{1-3)}$ including UNIV 1400 (for all organisms), EUB 338 (for Bacteria), ALF 1b (for a-Proteobacteria), BET 442a (for $\beta$-Proteobacteria), GAM 42a (for $\gamma$-Proteobacteria), HGC 69a (for high $\mathrm{G}+\mathrm{C}$ content gram-positive bacteria), ACA 23a (for Acinetobacter spp.), CF 319a (for Cytophaga-Flavobacterium), AER 66 (for Aeromonas), BAC 303 (for Bacteroides spp.) and P 72 (for Pseudomonas spp.) were used as probes.

\section{RESULTS AND DISCUSSION}

Total numbers of microbial cells in fecal samples of five goldfish ranged from $2.8 \times 10^{10}$ to $2.0 \times 10^{11}$ cells/g. As shown in Fig. 1, hybridization studies with the universal probe, UNIV 1400, showed that 84.6 to $96.8 \%$ of total bacteria in all fecal samples had the ribosomal content enough to produce strong hybridization signals, suggesting that the majority of the microbial populations inhabiting goldfish intestines are metabolically active. The microbial cells in all samples reacted with EUB 338, ALF 1b, BET 42a, GAM 42a, ACA 23a, AER 66 and BAC 303 probes. This result strongly suggests that goldfish intestinal bacteria are mainly composed of the $\alpha$-, $\beta$ - and $\gamma$-subgroups of the Proteobacteria and CFB group. In the previous paper, ${ }^{4)}$ we reported that intestinal microflora of goldfish are mainly composed of Aeromonas hydrophila and Bacteroides type A, and are characterized by great daily fluctuations and individual-to-individual variations. A preliminary experiment showed that cells of Aeromonas spp. and Bacteroides type A are stained with AER 66 and BAC 303, respectively. These results strongly suggest that Aeromonas spp. and Bacteroidaceae were detected as predominant bacteria in goldfish intestines by the FISH method, as well as the culture technique. 


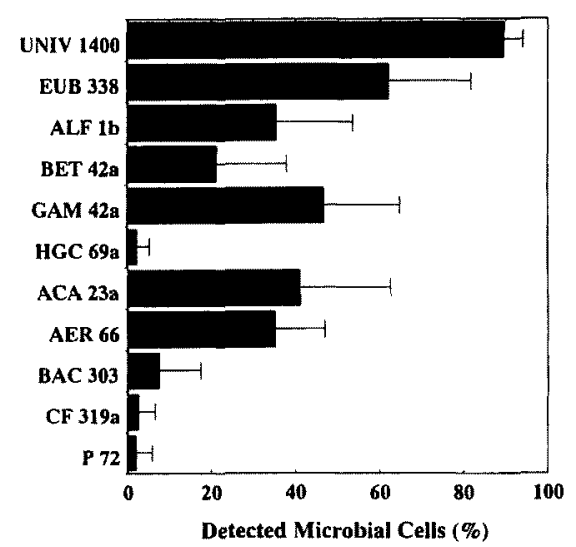

Fig. 1 Microbial composition of fecal samples of goldfish, determined with 11 fluorescently labeled rRNA-targeted oligonucleotide probes. Total numbers of microbial cells stained with DAPI were regarded as $100 \%$. Error bars represent SD of the means $(n=5)$.

One of the most important theme in intestinal bacteriology is what is the role of bacteria in the intestinal tract. In such studies, however, a great number of bacteria are subjected to be isolated and identified. As identification of intestinal bacteria is time-consuming and labor intensive, this step is the greatest barrier for studying intestinal bacteria. In addition, about a half bacterial cells in fish intestines seem to be unculturable. ${ }^{5)}$ The present study demonstrated that the FISH method using rRNA-targeting probes are useful for determination of intestinal microlfora of fish. However, this method needs phylogenetic data of almost all intestinal bacteria for designing rRNA-targeted oligo-nucleotide probes. Further studies along this line are in progress.

In conclusion, the FISH method using rRNA-targeting probes has provided new information on the intestinal microflora of fish. This method will help to refine current knowledge about the composition and dynamics of the flora.

\section{ACKNOWLEDGEMENTS}

This study was supported in part by the Nihon University Research Grant for 2001, a Grant-in-Aid for Scientific Research from the Japan Society for the Promotion of Science, and 'High-tech Research Center Project' of Nihon University supported by the Ministry of Education, Culture, Sports, Science and Technology of Japan.

\section{REFERENCES}

1. Akkermans $\mathrm{ADC}$, van Elsas JD, de Bruijn FJ (Ed). Molecular Microbial Ecology Manual. Kluwer Academic Publishers, Dordrecht. 1995.

2. Manz W, Aman R, Ludwig W, Vancanneyt, Schleifer KH. Application of a suite of $16 \mathrm{~S}$ rRNA-specific oligonucleotide probes designed to investigate bacteria of the phylum cytophaga-flavobacter-bacteroides in the natural environment. Microbiology 1996;142: 1097-1106.

3. Santo Domingo JW, Kaufman MG, Klug MJ, Tiedje JM. Characterization of the cricket hindgut microbiota with fluorescently labeled rRNA-targeted oligonucleotide probes. Appl. Environ. Microbiol. 1998;64:752-755.

4. Sugita $H$, Fukumoto $M$, Tsunohara $M$, Deguchi Y. The fluctuation of the fecal flora of goldfish Carassius auratus. Nippon Suisan Gakkaishi 1987;53:1443-1447.

5. Sugita H, Sakata T, Ishida $Y$, Deguchi $Y$, Kadota $H$. Measurement of total viable counts in the gasto-intestinal bacteria of freshwater fish. Nippon Suisan Gakkaishi 1981;47:555. 